\title{
RESSIGNIFICAÇÃO DAS POLÍTICAS, FUNDAMENTOS E PROCESSOS DA CIÊNCIA DA INFORMAÇÃO APORTADA PELAS TECNOLOGIAS DA INFORMAÇÃO E COMUNICAÇÃO: ENSAIO AVALIATIVO
}

\begin{abstract}
Resumo: Nesse ensaio, ressalta-se o expressivo significado que as tecnologias de informação e comunicação promoveram no desenvolvimento dos países, sobretudo no que tange ao bem-estar dos cidadãos, à geração de capital social e à criação e sustentação de projetos estruturantes. A disponibilização da banda larga, o acesso gratuito à internet, a universalização da educação digital são exemplos de recursos informacionais, que associados a outras medidas incentivadoras, como o ensino do empreendedorismo nas escolas, os estímulos ao aparecimento de inventores, fizeram surgir iniciativas compartilhadas, como as incubadores de empresas e os parques tecnológicos. A esse contexto tecnológico inovador, associa-se o uso de novos processos automatizados de tratamento da informação pelas bibliotecas, com o propósito de organizar e disponibilizar o incomensurável volume de informações, de modo quase que customizado, porque baseado nos modelos cognitivos de busca da informação pelo usuário, a partir do desenvolvimento de sistemas automáticos de armazenamento e recuperação da informação.
\end{abstract}

Lídia Maria Batista Brandão Toutain Doutorara em Filosofia pela Universidade de Lion Professora Titular do Instituto de Ciência da Informação, da Universidade Federal da Bahia lbrandaotoutain@gmail.com

Palavras-chave: Política de informação. Informação e sociedade.

Educação Digital.

\section{REFRAMING OF INFORMATION SCIENCE POLICIES, FOUNDATIONS AND PROCESSES BROUGHT BY INFORMATION AND COMMUNICATION TECHNOLOGIES}

\begin{abstract}
Abstrac: This essay highlights the significance that information and communication technologies have promoted in the development of countries, especially with regard to the well-being of citizens, the generation of social capital and the creation and support of structuring projects. The availability of broad band, free internet access, the universalization of digital education are examples of informational resources, which combined with other encouraging measures, such as teaching entrepreneurship in schools, encouraging the emergence of inventors, gaverise to share dinitiatives, such as business incubatorsand technology parks. This innovative technological context is associated with the use of new automated processes of information handlingby libraries, with the purpose of organizing and making available theim measurable volume of information, almost customized, because based on the cognitive models of information search by theuser, through the development of automatic information storage and retrieval systems.
\end{abstract}

Keywords: Information policy. Information and society. Digital education. 


\section{INTRODUÇÃO}

Nesse artigo, procura-se analisar como o progresso tecnológico é de importância decisiva para o crescimento econômico e social e ressignifica os processos de informação e comunicação. Em seguida, mostra-se como os aparatos tecnológicos se refletem no mundo das ideias e das coisas. O conceito de ideias, segundo Romer, está intimamente relacionado ao de introspecções, que podem ser compartilhadas por muitas pessoas. Já as coisas, cuja acepção é a de produtos, não podem ser amplamente compartilhadas.

Sabe-se que a informação e a comunicação constituem a matéria-prima da chamada nova economia, porque são ativos intangíveis, insumos comparáveis à energia que alimenta um sistema. Nessa medida, ambas condicionam a operacionalidade dessa nova economia, bem como, o papel da ciência, da tecnologia e da cultura. Elas são reconhecidas como elementos fundamentais para o desenvolvimento econômico e social, especialmente, após o advento da internet e da teia mundial, a World Wide Web.

Robredo (2010), revisitando a história da internet, traça breve esboço do desenvolvimento das tecnologias da informação e da comunicação, principalmente ao referirse à $W E B$ semântica. Ele cita:

[...] merece uma pausa para pensar o que a WEB semântica teria para contribuir com o futuro desenvolvimento da ciência da informação, bem como seus desdobramentos e aplicações. Começou-se a falar da WWW quando a Internet se consolidou como uma realidade que ultrapassava os limites conceituais do seu idealizado, Tim Berners-Lee (1989) e, tornando realidade os sonhos ou premonições de Paul Otlet (1925) e de Vannevar Bush (1945). O primeiro com o seu MUNDANEUM (inaugurado em 1919, que veio a ser chamado por Rayward (2002) de "internet de papel”, e o segundo [...] em 1945, onde descreve sua engenhoca denominada Memex (Memory Expanded), para alguns, a ideia do primeiro sistema hipertextual multimídia).

Nesse contexto, merece destaque o artigo escrito, em 1945, por Vannevar Bush, pesquisador do MIT, que aponta o problema da explosão informacional e distingue como ponto crítico a incapacidade dos meios e técnicas conhecidos, de facilitar o acesso às informações úteis, de modo eficiente. Foi também quando Bush propôs a criação da máquina Memex, acima citada por Robredo, e que, segundo Bush, tinha a funcionalidade de associar ideias, com a capacidade de "duplicar os processos mentais artificialmente".

Saracevic considera este um fato marcante e indicativo do nascimento da CI. Sobre isto ele sintetiza: "É bastante evidente a antecipação do nascimento da CI e, até mesmo, da inteligência artificial". 
Sobre este imperativo da tecnologia da informação, Tefko Saracevic, em um texto emblemático, escrito em 1996, afirma que a Ciência da Informação está inexoravelmente ligada às tecnologias da informação e da comunicação e determinada por ela. Olhando a CI por outro ângulo, com o propósito de delimitar seus fundamentos, Robredo (2011) assevera que os fundamentos da ciência da informação estão entrelaçados com a representação da informação. Ele assim se posiciona:

É no estudo da representação e organização da informação e do conhecimento que se encontrarão os fundamentos da ciência da informação. É sempre alguma linguagem (natural, verbal, escrita, artificial, etc.) ou código de sinais do tipo que for, que permite externar o conhecimento, comunicar, registrar e transmitir a informação, que, por sua vez, via interação de novas informações com os conhecimentos individuais ou coletivos já adquiridos, gera novos conhecimentos. (ROBREDO, 2011).

No artigo antes citado, Saracevic (1996) aponta outras características da ciência da informação, como sua natureza interdisciplinar, e a tendência a que esta interdisciplinaridade continue se ampliando, destaca ainda a forte possibilidade de a CI, por sua dimensão social e humana, contribuir com o desenvolvimento da Sociedade da Informação, que começa a despontar.

Na verdade, a CI, embora não se possa precisar o tempo exato do seu surgimento, nasce em um conturbado momento da vida da humanidade, ou entre o interstício das duas grandes guerras ou mesmo no front da Segunda Guerra Mundial, ou logo após seu término, no início da Guerra Fria, travada entre a extinta União Soviética e os Estados Unidos. Era um momento de ideologias políticas, econômicas e sociais fortes, às quais vieram dar vazão um intenso cabedal de conhecimento resultante das revoluções científicas ocorridas em séculos anteriores e da Revolução Industrial, ocorrida na Inglaterra nos meados do séc. XVIII e no resto do mundo, a partir do séc. XIX. Mas este é um momento particular e significativo de intensa produção científica e de apropriação do conhecimento para fins pragmáticos - a guerra. Deste esforço, resultou um grande acúmulo de informação científica.

Robredo (2011) tece profundas considerações sobre este momento e esclarecendo os fatos, diz:

As descobertas científicas dos anos da transição do século XIX para o século XX aceleram a produção de documentos científicos e nascem, nos anos que separam as duas grandes guerras (1918-1939), os primeiros serviços de documentação científica. O crescimento explosivo da documentação, resultante do interesse dos países vencedores da Segunda Guerra Mundial, por desvendar e explorar o conteúdo dos documentos dos arquivos técnicos e científicos da Alemanha, resultou no crescimento também explosivo dos 
centros de documentação, e no surgimento dos sistemas de informação setoriais, agora com uma forte intenção colaborativa entre países, sob o impulso dos organismos internacionais, especialmente aqueles da família das Nações Unidas.

Pode-se perceber também que este é o momento em que a informação assegura seu estatuto de tema científico, e ao mesmo tempo, realçam-se seus valores estratégicos e competitivos. É neste clima ainda de insegurança civil que os líderes e estrategistas percebem a necessidade de controlar, não no sentido de freiar a produção, mas de ter controle/domínio do que é produzido, do que existe e de como localizar e ter acesso às informações científicas acumuladas, de modo que elas pudessem servir de subsídio, no momento oportuno, para pessoas autorizadas. Ou seja, que elas estivessem potencialmente prontas para cair em mãos certas.

Havia então um problema: a chamada explosão da informação e o que estava posto para os cientistas daquela época era: "a tarefa massiva de tornar mais acessível, um acervo crescente de conhecimento" (palavras de Vannevar Bush). Sobre isto, Saracevic (1996) declarou:

Cientistas e engenheiros de todo o mundo, e os mais importantes governos e agências de financiamento em muitos países ouviram e agiram. Nos Estados Unidos, o Congresso e outras agências governamentais aprovaram, durante os anos 50 e 60, inúmeros programas estratégicos que financiaram os esforços em larga escala para controlar a explosão informacional, primeiro na ciência e tecnologia, e depois em todos os outros campos. Empresas privadas uniramse a eles. Eventualmente, esses programas e esforços foram responsáveis pelo desenvolvimento da moderna indústria da informação e das concepções que a direcionam.

Permitam-me continuar citando ainda Saracevic, porque, como disse, este texto é emblemático. A respeito do posto a que a informação é alçada naquele momento, Saracevic (1996) diz:

\begin{abstract}
A lógica estratégica original que fundamentou tais programas e esforços era a seguinte: uma vez que a ciência e a tecnologia são críticas para a sociedade (por exemplo, para a economia, saúde, comércio, defesa) é também crítico prover os meios para o fornecimento de informações relevantes para indivíduos, grupos e organizaçõesenvolvidas com a ciência e a tecnologia, já que a informação é um dos mais importantes insumos para se atingir e sustentar o desenvolvimento em tais áreas. Posteriormente, essa justificativa, baseada na importância estratégica da informação, foi estendida a todos os campos, a todas as tarefas humanas e a todos os tipos de empreendimentos. Esta justificativa foi e é aplicada globalmente.
\end{abstract}

Desde então, o assunto foi alvo de estudos e muitas soluções teóricas, técnicas e recursos operacionais e práticos foram experimentados e postos em prática e até muitos foram superados.

Em 1951, Calvin Mooers (apud SARACEVIC, 1996) aplicou a expressão recuperação da informação e explicou que ela "engloba os aspectos intelectuais da descrição de informações 
e suas especificidades para a busca, além de quaisquer sistemas, técnicas ou máquinas empregados para o desempenho da operação."

Para Saracevic, o âmago desta questão passa por três perguntas, a saber: a) como descrever intelectualmente a informação? b) como especificar intelectualmente a busca? c) que sistemas, técnicas ou máquinas devem ser empregados?

Nos dias atuais, em que o conceito de web semântica está se destacando como meio de recuperação da informação, pode-se perceber ainda a atualidade desta questão: Porque e para que servem metadados, ontologias, taxonomias, linguagens de marcação etc.? E mais especificamente na nossa área, o que são Requisitos Funcionais para Registros Bibliográficos (FRBR), Requisitos Funcionais para Dados de Autoridade (FRAD), Descrição e Acesso aos Recursos (RDA), senão conceitos, técnicas, modelos, meios, instrumentos, sistemas para responder a estas perguntas?

Tem razão Saracevic (1996) quando declara

De tais questões, surgiu uma grande variedade de conceitos e construtosteóricos, empíricos e pragmáticos, bem como numerosas realizações práticas. Muitos exemplos históricos podem ilustrar a marcante evolução de sistemas, técnicas e/ou máquinas utilizados para recuperação da informação. Sua variedade vai dos cartões perfurados aos CD-ROMs e acesso online; dos sistemas não-interativos àqueles de múltiplas possibilidades de interação, com interfaces inteligentes, transformando a recuperação de informação em um processo altamente interativo; de bases documentais para bases de conhecimento; dos textos escritos aos multimídia; da recuperação de citações à recuperação de textos completos; e ainda aos sistemas inteligentes e de respostas a perguntas.

Até então, décadas de 50 e 60, do século passado, vê-se nitidamente que o paradigma da CI assentava-se em duas variáveis: a recuperação da informação e a tecnologia que possibilitava esta recuperação e, neste âmbito, destacam-se especialistas como Vickery, Lancaster, Albright, Aitchison, Borko, Holmes, Jacobs, Myers, o próprio Saracevic e outros.

No entanto, a partir da década de 70, outra variável, que sempre esteve latente nos conceitos e no fazer da ciência da informação vem se somar, de modo explícito, aos outros dois: o usuário. Isto porque fica claro que a CI medra no terreno da comunicação humana. Ou seja: - quem comunica a informação e para que uso? Ainda que haja a consecução da máquina, o receptor é sempre o usuário. Alguns autores se manifestaram sobre este ponto nevrálgico, dentre eles: Belkin e Robertson (1976), que assim se expressaram: "O propósito da CI é facilitar a comunicação de informações entre seres humanos.” E Becker (1976) considera que cabe à CI estudar o modo como as pessoas "criam, usam e comunicam informações”, buscando soluções 
conceituais e tecnológicas que viabilizem este processo. Já Kochen (1974) insere o processo de recuperação da informação no âmbito de um sistema de conhecimento mais amplo, constituído de três partes: (a) as pessoas em seu papel de processadores de informações; (b) os documentos em seu papel de suportes de informações; (c) os tópicos como representações. Wersig e Nevelllng (1975) chamam a atenção para o fato que motiva o desenvolvimento da CI, apontando a relevância que a informação passou a ter para a sociedade e concluíram "atualmente, transmitir o conhecimento para aqueles que dele necessitam é uma responsabilidade social, e essa responsabilidade social parece ser o verdadeiro fundamento da CI".

Nesta perspectiva de considerar o usuário o propósito primordial, a CI se aproxima das teorias educacionais e cognitivas e muitos especialistas da área debruçam-se sobre este assunto, tais como, Wilson, Belkin, Brenda Dervin, Carol Kuhlthau, Choo etc.

Diante deste universo complexo, Saracevic (1996) considerou necessário redefinir a CI, observando sua evolução, e assim a enuncia:

[...] a ciência da informação é um campo dedicado às questões científicas e à prática profissional voltadas para os problemas da efetiva comunicação do conhecimento e de seus registros entre os seres humanos, no contexto social, institucional ou individual do uso e das necessidades de informação. No tratamento destas questões são consideradas de particular interesse as vantagens das modernas tecnologias informacionais.

Preocupado em demarcar os problemas de pesquisa e a prática profissional da CI, assim como seus limites, Saracevic levanta as palavras-chave, a partir de sua definição e as enumerou: a) efetividade; b) comunicação humana; c) conhecimento; d) registros do conhecimento; e) informação; f) necessidades de informação ;g) usos da informação; h) contexto social; i) contexto institucional j) contexto individual; k) tecnologia da informação.

E mirando este vasto, complexo e multidisciplinar campo de estudo eu ouso acrescentar os termos: usuário, cognição e aprendizagem; tendo em vista que a ciência da informação aumentou, sobremaneira, seus limites, não estando hoje restrita à comunicação científica, abarcando também a comunicação social; também porque a sociedade da informação é hoje percebida como sociedade da aprendizagem, e neste âmbito se discutem as nuances da aprendizagem duradoura e permanente; e a cognição, porque este conhecimento é intrínseco à condição da aprendizagem. Também porque é nitidamente didático o processo de buscarecuperação e uso da informação e sua transformação em conhecimento. 
Estes são, pois, os pressupostos sobre os quais a CI se assenta. Na verdade, os pilares básicos: 1) A Representação/Recuperação da Informação - com os princípios, teorias, técnicas, modelos e aparatos que envolvem este processo de dupla face, sim, porque é preciso representar a informação, para recuperá-la. É nesta fase também que se concretiza o princípio da Preservação/Cumulação do Conhecimento (por meio do seu registro) e de Sua Transmissão (para a sociedade, para a comunidade científica, para o sujeito aprendente); 2) Os Estudos de Usuários e da Comunicação Humana - englobando, inclusive, os modos, as estratégias de busca, recuperação e uso da informação e seu envolvimento com as estratégias intelectuais, a aprendizagem, a cognição; e, por fim, 3) a Tecnologia - que permite a representação, recuperação e acesso à informação, inclusive otimizando as condições. Esta é a tríade, a teia, que, em tese, tece o pano de fundo, o cenário, os limites da Ciência da Informação.

No entanto, no mundo contemporâneo, a tecnologia parece sobrepujar todos os demais elementos, todas as demais variáveis. Todos somos atraídos por ela. -É o domador de serpente - que nos encanta com seu poder mágico - que nos atrai com sua nuance de entretenimento.

Este é um caso para ser explicado pela Antropologia. O professor Darcy Ribeiro, em seu livro, O processo civilizatório (2000), explica a evolução da humanidade mediante as revoluções tecnológicas, ou seja, a tecnologia da época é determinante na evolução sociocultural do grupo. Darcy Ribeiro se refere ao "movimento histórico de mudança dos modos de ser e de viver dos grupos humanos, desencadeado pelo impacto de sucessivas revoluções tecnológicas sobre as sociedades" (RIBEIRO, 2000, p. 15).

De algum modo, Pierre Lèvy, em as Tecnologias da Inteligência (1998) corrobora o pensamento de Darcy Ribeiro, na medida em que defende a idéia de que, modernamente, as tecnologias da informação e da comunicação determinaram a instituição de uma inteligência coletiva/ de um conhecimento coletivo. É como se a Internet fosse uma enciclopédia global, que envolve toda a humanidade, na qual todos contribuem, ou, pelo menos, têm direito de contribuir.

Este fato explica a expansão dos limites da Ciência da Informação, que agora não se ocupa apenas do conhecimento científico, acadêmico. Ela transcende o campo da ciência, como temática de estudo, e se volta também para a informação produzida pelos grupos sociais, pelo conhecimento da sociedade em geral, para a comunicação social.

\section{O IMPACTO DAS TECNOLOGIAS DE INFORMAÇÃO E COMUNICAÇÃO NA EVOLUÇÃO DA SOCIEDADE}


Atualmente, como se sabe, a ciência, a tecnologia e a inovação têm um papel crucial na criação de riqueza, no crescimento econômico, na educação e na melhoria da qualidade de vida de todos os cidadãos. Na medida em que criam trabalho e bem-estar através de novos bens e serviços, e de sua comercialização, a ciência, a tecnologia e a inovação - ao atuarem de modo combinado - ajudam a reduzir a pobreza, a melhorar a saúde, a educação, os processos de ensino/aprendizagem, a alimentação e as relações comerciais, razão pela qual elas são indispensáveis para a construção de novas capacidades, essenciais no século XXI.

Ora, se este é o atual contexto do mundo, o que está em jogo é uma vinculação, cada vez maior e mais intensa, entre as políticas de comunicação, informação e cultura e a noção de criatividade. É fato elementar que tudo que se faz na sociedade de nossos dias depende de processos informatizados. O Brasil é um dos países que participam ativamente dessa nova realidade mundial. Seus cidadãos, em número já bastante expressivo, têm acesso à internet e a algum tipo de rede social. As TIC, por sua vez, e de acordo com suas próprias características, estão em constante processo de transformação.

Pergunta-se: as novas tecnologias substituem as já existentes ou a estas se somam? $\mathrm{Na}$ medida em que elas são novas, sua comprovação e sua eficácia se mostram naquilo que é essencialmente criativo e na expansão da criatividade. Não há limite para a descoberta do novo. O desafio é: como utilizar as novas tecnologias em projetos, por exemplo, de cidades criativas, como instrumentos comunitários que apoiam tanto a criação de "clusters" (agrupamentos de empresas), quanto de veículos para a criatividade e a inovação, a mobilidade e a transferência de conhecimentos?

As mídias sociais, que já identificam os potenciais de uma sociedade acada vez mais participativa, incentivam a criação, o compartilhamento, a avaliação e a atualização de conhecimentos por meio de interações permanentes entre seus cidadãos, a respeito de ideais comuns e de problemas comuns. Podem, por isso mesmo, possibilitar rapidamente uma outra visão desses problemas, em algum ponto da comunidade, e encontrar respostas em tempo real.

Cabe, entretanto, observar que isto só é possivel devido ao acesso à informação, a qualquer momento, em qualquer lugar, neste contexto mundial. Santaella (2007), em seu livro Linguagens Líquidas na Era da Mobilidade, assinala: "É para essa direção que aponta a evolução dos aparelhos moveis [...] Os equipamentos tornam absolutamente ubíquos o acesso à informação, à comunicação e à aquisição de conhecimento.”

Daí o desafio que se apresenta: potencializar o uso das redes, pois as novas tecnologias oferecem acesso, mecanismos de busca e organização de conteúdo, interação digital . Seus 
benefícios só se verificam quando são balizados pelos processos de informação e as políticas são aplicadas, assim como as atividades e ações desenvolvidas pelos usuários.

Convém notar que, por um lado, o acesso rápido e fácil, possibilitado pelas tecnologias de transmissão, pressupõe: questionar a qualidade da informação disponível e o uso que se faz dela, discernir e escolher as informações e fontes de pesquisa, separar e descartar o lixo eletrônico e selecionar o que realmente tem conteúdo, enfim selecionar aquilo que o usuário realmente precisa.

Santaella (2007), no livro há pouco referido, afirma que nenhuma tecnologia da linguagem da comunicação suprime as tecnologias anteriores. Esta afirmação pode ser comprovada historicamente, ao longo do processo multimilenar, a partir do momento em que a espécie humana se desprendeu de sua condição animal: a comunicação e a informação são veiculadas primeiro pelos gestos, a mímica; depois, pela linguagem articulada, com o agenciamento dos signos; em seguida, com a grande revolução do alfabeto, pela escrita, e só muito tempo depois pela impressão, criada por Gutenberg. Do século XIX até hoje se acompanha o crescimento constante das mídias e sua ressignificação, o que provoca a diversificação das tecnologias de transmissão e as possibilidades diferenciadas de aplicação e de conteúdo.

Pode-se verificar um retorno do uso corporal como o toque, a voz ou outros movimentos do corpo utilizados na operação dos novos equipamentos: os tabletes, netbooks, ipods, celulares multimídias, após a eliminação de fios, de teclados e de comandos, o que tem tornado os mecanismos de comunicação cada vez mais sofisticados, eficazes e eficientes.

Entretanto, a proposta de interação digital e sua facilidade de acesso não garantem ou representam melhores modelos de ensino, nem estão ao alcance da economia criativa. Tudo vai funcionar a depender de como se faz a aplicação e como se utiliza os novos equipamentos.

Vejamos agora uma experiência que se realiza no Brasil. O governo do Paraná criou o programa Curitiba 2030, no âmbito do que chamou de Cidades Inovadoras da Federação das Indústrias do Paraná (FIEP). O que é uma "cidade inovadora"? É, fundamentalmente, uma cidade centrada nas pessoas. A diferença entre uma "cidade" e uma "cidade inovadora" reside nas pessoas que as habitam e no modo como constroem esses ambientes. Trata-se, no caso do Paraná, de indicar caminhos para a criação de um ambiente urbano propício à inovação, ao desenvolvimento das potencialidades humanas e ao surgimento de novos negócios, em uma dinâmica de sinergia socioambiental.

Quais são condições de possibilidade para desenvolver projetos assim? Primeiro, proceder à abordagem participativa no processo; depois, identificar os eixos estruturantes e os 
vetores de transformação fundamentais para alcançar a visão de futuro; em seguida, mobilizar especialistas e cidadãos e comprometê-los com o futuro de sua cidade.

Não é mais possível planejar o futuro de uma cidade, por exemplo, sem os fundos locais de capital de risco, a acessibilidade aos transportes, a adoção de novas metodologias de ensinoaprendizagem, o uso de indicadores de desenvolvimento humano, a inclusão econômica de todos os cidadãos, a sustentabilidade ambiental e o envolvimento das pessoas que vivem o cotidiano dessa cidade.

O referido projeto paranaense, iniciado em 2010, fez diagnósticos circunstaciados da situação atual, realizou pesquisas sobre cidades que já elaboraram estudos similares, além de identificar e analisar tendências e fatores de mudança que moldarão o futuro das cidades nos próximos 15 a 20 anos. Essas informações básicas, segundo a FIEP, possibilitarão a análise da situação de Curitiba em relação a outras cidades e às tendências de futuro, bem como do processo de transformação em uma cidade inovadora, num horizonte de longo prazo.

Rodrigo Lures (2011), um dos participantes desse projeto, sublinha: “(...) conectividade e interação são palavras de ordem da cidade em rede. Curitiba visa a ser referência internacional no uso de redes para sustentar o desenvolvimento dos cidadãos e das organizações."

Dessas considerações, depreende-se que uma cidade do conhecimento é aquela que cria condições de autossustentabilidade, mantém vínculos permanentes com cidades semelhantes. O pressuposto básico é que a geração de conhecimento pode gerar desenvolvimento local, sendo necessária a existência de infraestrutura de redes e tecnologias de informação e comunicação, e uma cultura de compartilhamento.

De acordo com esses autores, os seguintes elementos são essenciais a uma cidade do conhecimento: uma forte dinâmica de suporte à inovação; educação de qualidade; envolvimento do cidadão com o desenvolvimento da cidade, incluindo sua identidade; e criação de um ambiente tolerante a minorias e imigrantes.

Cabe observar, porém, que as cidades criativas não devem ser definidas apenas em função de seu desenvolvimento tecnológico. A existência de uma forte economia cultural e de indústrias criativas bem desenvolvidas também podem ser elementos definidores desse conceito.

A sugestão proposta pelo conceito de cidades criativas seria a criação real ou imaginária de uma ação política dominante, como a praticada em Toronto, no Canadá. Ou seja, um modelo único e poderoso de construção de cidade por um líder coletivo. Uma cidade assim, com um número expressivo de empresários locais praticando a liderança coletiva, torna-se capaz de fazer frente a seus desafios e de realizar projetos, os mais diversificados, nos setores econômico, 
social, educativo, artístico e ambiental. Ora, fazer isso é capitalizar o que há de rico nas divers idades.

\section{PRÁTICAS INOVADORAS E A ERA NOÉTICA}

Neste contexto de crescente competitividade e de importantes desafios em nível global, as práticas inovadoras e as soluções criativas procuram alavancar o crescimento e, nessa medida, contribuir significativamente para o bem-estar das regiões e dos países.Competências, ideias e processos são aspectos que podem e devem ser combinados na busca de obtenção de vantagens no jogo da competitividade intensa.

O Brasil precisa - e muito, o que é mais do que óbvio - investir em competências e inovação. Ter a ousadia de confiar na qualidade de suas ideias e em sua capacidade de adaptação. Deve, também, com efeito, fazer com que o financiamento público disponível funcione melhor e produza melhores resultados.

Nossa premência é pensar em escala global e promover a criatividade e a inovação em diferentes níveis, o que requer a melhoria profunda de nosso sistema escolar básico, investimentos maciços na política de produção científica. A criatividade e a inovação são também uma questão de mentalidade: aqueles que só se interessam pelos seus próprios domínios e pela maneira de progredir neles, estão condenados ao fracasso. O mais importante, em nível de criatividade, é precisamente "sair dos caminhos trilhados", abandonar os quadros do pensamento compartimentado, como nos convida Marc Halévy (2010).

Neste contexto, Boaventura Santos (2003) propõe o que chama de "paradigma emergente", o qual confere às ciências sociais um novo papel, na busca de um novo senso comum. Daí, sua crítica ao modelo científico dominante, fundado na epistemologia positivista.

Perceber o mundo à luz desse novo paradigma - que envolve tantas conexões - , é percebê-lo cada vez mais rapidamente. Essa percepção não é outra coisa senão o que se traduz em inovação.Como as coisas mudam, não sabemos; como isto ou aquilo vai se comportar, também não sabemos — mas sim, o que é próprio da história humana, que somos capazes de nos adaptar a situações novas.

Eis o que Halévy chama de "era noética" (termo que, em grego, significa mente):

[...] nome que damos [...] ao novo paradigma [...] em especial na forma da sociedade do conhecimento e da informação e em substituição à era moderna (e à sociedade industrial).Por era moderna devemos entender "modernidade como continuação da Idade Média", que desde o Renascimento até a queda do 
muro de Berlim [...] produziu a economia industrial e capitalista, a política estatistita e colonial, e que se alimenta do pensamento cartesiano, isto é, do pensamento racionalista, analítico, mecanicista e determinista). A era noética começa com a superação de toda essa "modernidade" em todos os planos, sobretudo o econômico, político e epistemológico (HALEVY, 2010, p.175).

Como assinala Halévy, o evolucionismo revoluciona de ponta a ponta nossa relação com o tempo. De acordo com Ilya Prigogine e Isabelle Stengers, citados por Halévy (2010), complexidade e evolução são conceitos intimamente ligados, razão pela qual “[...] se há uma lei acima e a montante de todas as leis, é a da complexificação cósmica global: o universo vai do menos ao mais complexo, em toda parte, em tudo, sempre".

Ao perceber o profundo impacto que o evolucionismo provoca nas certezas ocidentais, Halévy nos convida a assumir, tal como o fizeram Heráclito (dizia que o tempo era móvel) e Nietzsche (o ser humano faz parte do mundo, não é o centro do mundo), a impermanência e a incerteza e a nos alimentar de mistério e de desconhecimento (ou seja, tem coisas que existem mas não poderia provar), para avançar mar adentro.

É ainda Halévy (2010, p.53) quem nos instiga a pensar, mostrando-nos o que acontece com a noosfera, conceito preconizado por Teilhard de Chardin (2006) como conjunto das redes de idéias e conhecimento em que se desenvolvem os processos de criação.

[...] a noosfera está latente desde a origem dos tempos, mas não podia surgir enquanto certas condições de "saturação" não fossem preenchidas dentro da memória cósmica. Foi preciso aguardar o aparecimento de uma densidade suficiente de matéria muito informada para que o processo se iniciasse. [...] [Na continuação da citação, grifamos:] o cérebro do homem, espantosamente mais complexo que o dos outros animais, foi um sinal de grandeza planetária. Mas, o início real da era noética na Terra ainda teve de esperar que as tecnologias da informação e da comunicação (TICs), inventadas pelo homem, fossem potentes o bastante para ligar entre eles esses cérebros antes limitados às esferas de voz (de pequeno alcance) e do livro (pesado, caro e raro). A era noética, que começa com o surgimento dessas TICs, marca a aceleração espetacular da saída da noosfera do estado de latência na Terra. (HALÉVY, 2010, p.53).

Halélvy sublinha que o ser humano precisa desenvolver o cérebro criativo, o qual funciona plenamente com seus hemisférios, o que aponta para a inovação, o uso de mais potencialidades e vai ao encontro das novas TIC. Não se trata mais do pensamento binário, já esgotado. O que está em jogo não é mais Sim versus Não, Preto versus Branco, Alto versus Baixo - e, sim, múltiplas respostas. Deixa então de valer o pensamento vertical, que só se 
interessa pela comprovação empírica, e é cego às respostas laterais, que pressupõem a conexão de diferentes abordagens e saberes.

Em 2016, Harari (2016, p.370) dizia que "segundo o dataísmo, o Universo consiste num fluxo de dados e o valor de qualquer fenômeno é determinado por sua contribuição ao processamento de dados". Aprofundando mais seu estudo conclui que

1. A ciência está convergindo para um dogma que abrange tudo e que diz que organismos são algoritmos, e a vida, processamento de dados; 2 a inteligência está se desacoplando da consciência; 3. Algoritmos não conscientes mas altamente inteligentes poderão, em breve, nos conhecer melhor do que nós mesmos. (HARARI, 2016, p.398)

A tecnologia da informação e comunicação evoluiu em seus três marcos fundamentais: o de suporte operacional e transformacional de dados, o de informação e conhecimento e o de usuários finais e gestores das organizações. Não por outro motivo, conhecer, numa era como esta, é incorporar o conhecimento como a principal ferramenta capaz de agregar valor aos processos, produtos e serviços.

Um fato é bem evidente: o sucesso de um negócio, hoje, é cada vez mais dependente da criatividade. Nos anos 1990, em vez de se privilegiar o talento dos indivíduos, sua capacidade de gerar novas idéias, a atenção voltava-se inteiramente para o uso puro e simples das tecnologias, como se a solução delas viesse, e não das pessoas. Com o advento das redes, começaram a mudar as formas tradicionais de organizar negócios nas empresas.

As empresas e as pessoas sentiram a necessidade de trabalhar juntas, compartilhar e proteger as novas ideias. Com essa percepção, foram surgindo os cibernegócios e as redes informais dentro e entre as organizações, o que é de importância seminal para a chamada "economia criativa" (creative economy), conceito criado pelo consultor britânico John Howkins

A economia criativa atua principalmente no setor de entretenimento, arte e negócios, mas é na verdade todo negócio que utiliza ideias para criar algo novo, principalmente quando essas ideias são protegidas pela legislação de direitos autorais (copyright). Justamente por isso, a criatividade, numa economia assim, vem a ser um dos valores complementares: ela se constitui com o valor da propriedade intelectual, intangível.

Não por outro motivo, os negócios passaram a ter novos experts e os gerentes de negócio dispõem-se a entender de diferentes sistemas de valor, por tudo que tem implicações no design organizacional, na estratégia, nas práticas de gestão e nas tecnologias em uso. Só com ideias é possível configurar-se uma comunidade de negócios vibrante e competitiva. 
O fazer científico também se tornou criativamente global, na medida em que requer, cada vez mais, relações de troca e de ressonância mútua. Produzir conhecimentos, hoje, e veiculá-los em publicações especializadas acessíveis são as duas faces da mesma moeda. A criatividade é, por isso, irmã gêmea da cooperação entre centros de excelência. O que então se percebe, tanto em âmbito regional quanto mundial, é o estímulo à cooperação entre pesquisadores dos mais distintos lugares. A pesquisa, o desenvolvimento e as indústrias criativas podem - e devem - ser, por isso mesmo, encorajados, assim como os clusters, e abrir-se à participação maior da sociedade.

Se a economia criativa e sua moeda corrente é a inovação, já existem, e em número crescente, estudos e análises de avanços em inovações "leves", a exemplo dos de setores como o de publicações, moda, jogos eletrônicos e indústrias fonográfica e videográfica. O que então se pergunta é: como analisar os ganhos trazidos por estes setores? E o que dizer de setores cujos produtos envolvem não apenas inovações, mas adaptações de conteúdos em ambientes de convergência tecnológica? A resposta a estas perguntas parece apontar para a necessidade de ampliação de novas pesquisas, visto que só o teste empírico desses novos índices pode dar credibilidade às propostas baseadas em inovações leves. Resposta, portanto, que só pode ser dada pelo próprio paradigma criativo, ou emergente, ou noético, ao continuar repensando (reestruturando) processos, produtos e serviços, a fim de incorporar adequadamente seu aporte de mudanças.

Desta forma, e à luz da ênfase que hoje se dá à criatividade em todos os setores, cabe uma reflexão sobre pesquisa e desenvolvimento $(\mathrm{P} \& \mathrm{D})$, conceito que, em linhas gerais, é entendido como um montante dedicado por empresas ou governos ao investimento em novas tecnologias. É evidente que, por um lado, quando se examinam os modos e meios pelos quais as TICs e o desenvolvimento sustentável se implicam, esse exame se reflete no campo das agendas públicas, seja por meio de linhas de apoio a centros de pesquisa ou universidades, seja por fomento a ambientes pró-inovação no setor privado, ou ainda nas parcerias públicoprivadas.

Harari (2018, p. 106), no seu mais recente livro 21 Lições Para O Século XXI, diz que, nesse século, a civilização pós-industrial baseada em inteligencia artificial, nanotecnologia e bioengenharia poderia ser muito mais autocontida e autossustentada.

Por outro lado, o que também se evidencia, nas diversas políticas, é a percepção de que percentuais mais elevados de pesquisa têm importância decisiva para o alcance das duas metas do planeta - a conservação da biodiversidade e a sustentabilidade do desenvolvimento em sua tripla dimensão: econômica, social e ambiental. 
Nessa dimensão, o mundo das ideias e das coisas, do qual falamos no inicio, evidenciase a partir daquilo que pode ser informado, como bem cita Buckland (1991), quando diz que aprendemos a partir do exame de várias coisas e enumera alguns tipos de elementos, com os quais aprendemos, ou seja, dados, objetos, textos e documentos, quando lemos, examinamos imagens, tocamos objetos etc. Também, o termo documento ou unidade documentária, segundo Otlet (1934), foi usado para denotar materiais e objetos informacionais, além da sua forma de armazenamento e recuperação da informação.

\section{CONSIDERAÇÕES FINAIS}

Em todo esse processo de informação, o que a ciência da informação tem a colaborar num mundo que trabalha com ativos intangíveis, como patentes, marcas, capital intelectual? Esta informação intangível, que vai garantir sua materialidade quando preservada nas bases de dados e nos repositórios informacionais, tornando-se ativos intangíveis, passa a ser o subsídio concreto da Ciência da informação, que desenvolve processos para a materialização dos dados.

Quando estas informações se tornam públicas, adquirem a natureza de - informação tangível -, pois está registrada em meios físicos ou digitais, podendo ser compartilhada, transmitida, difundida de forma cada vez mais refinada. Estes valores agregados se transformam em bens e precisam de registros, e nestas bases vão encontrar dados, informações para gerarem mais conhecimento, para busca de novas criações e invenções e, assim, pode ser medido e qualificado.

Neste contexto, é preciso criar processos e produtos cada vez mais sofisticados, com novos métodos, novas linguagens que auxiliem, assegurem, garantam a preservação, a criação, transmissão, circulação e difusão. Há aqui todo conjunto de domínio e de setores a atividade humana onde não cessa de desenvolver as relações humanas, mas também a invenção e a criação. O desafio para a CI é como adequar e utilizar esses meios em prol das práticas sociais e públicas, das realidades políticas, da economia e da memória social e cultural.

Para concluir, destaca-se que as tecnologias avançam cada vez mais, porém complementando-se, somando, se transformando, compartilhando recursos. O digital e o impresso coexistem em todos os meios - nas bibliotecas, nas empresas, nos museus.

O grande fantasma hoje é a quantidade de informação digital e seu armazenamento, como, por exemplo, os grandes repositórios de artes híbridas e bancos de dados, para onde vão todas estas informações onde estarão? Surgem então os provedores, que estão nas nuvens, onde 
estamos conectados de forma ubíqua e se transformam em energia, em átomo, como explicam as ciências quânticas.

É essa evolução que nos caracteriza e nos leva a novos paradigmas, que nos leva à evolução citada por Harari (2018), Boaventura Santos (2003), Mark Halevy (2010) e Robredo (2010, 2011) e tantos outros.

A informação é objeto de conteúdo e transmissão, talvez nunca se dissipe; é um pensamento abstrato, mas, com capacidade de exatidão, ela sempre estará lá; a questão é: com que segurança poderá ser recuperada, isso é inimaginável.

Por outro lado, o mundo digital está em constante evolução, é como se houvesse, deliberadamente, a busca contínua por uma revolução de princípios, métodos, técnicas, recursos, soluções. O fulcro da questão, porém, não são os objetos digitais e soluções isoladas, mas a interatividade que estas tecnologias propiciam e as muitas possibilidades que criam para o acesso à informação. São, portanto, ferramentas incrementadoras da comunicação social e científica e, portanto, um vasto campo de estudo da ciência da informação.

\section{REFERÊNCIAS}

BUCKLAND, M. Information as thing. 1991 (discute a ambiguidade da informação).

BUSH, V. As we may think. The Atlantic Monthly. v.176, p.101-108, jul.1945. Disponível em: http://www.theatlantic.com/. Acesso em: 10 out. 2003.

CURITIBA 2030. Rev. Cidades Inovadoras. São Paulo: Educação Brasil, 2011. Acesso em abril de 2011.

FERREIRA, F. Cidades globais, do conhecimento, criativas ou technopolis: um olhar sobre Austin e Salvador. Rev. Eletronica de Jornalismo Científico, São Paulo, SBPC, fev. 2011. Disponível em: http://www.dicyt.com/noticia/cidades-globais-do-conhecimento-criativas-outechnopolis-um-olhar-sobre-austin-e-salvador. Acesso em 5 set. 2011. 
HALÉVY, M. A era do conhecimento.Trad. Roberto Leal. São Paulo: UNESP, 2010.

HARARI,Y. Homo Deus: uma breve história do amanhã. Tradução de Paulo Geiger. São Paulo: Companhia das Letras, 2016. 398 p.

HARARI, Y. Sapiens: uma breve história da humanidade. Tradução de Janaina Marcoantonio. 3. ed. Porto Alegre: L\&PM, 2015. (Discute a evolução humana e biológica.)

HARARI, Y. As lições para o século XXI. Tradução de Paulo Geiger. São Paulo: Companhia das Letras, 2018.106 p. (Discute a mudança social no século XXI).

HARMAN, W. What Are Noetic Sciences? Institute of Noetic Sciences. Newsletter, v.6, n. 1, Spring 1978.

KELLY, K. Novas regras para a economia. Disponível em: http: kk.org.newrules. contents.Php. Acesso em: 20 out. 2011.

KOCHEN, M. Principies of information retrieval. Los Angeles: Melville, 1974.

OTLET, P. Traité de Documentation - Le livre sur le livre: théorie et pratique. Bruxelles: Mundaneum, 1934. $411 \mathrm{p}$.

LEMOS, R.; SANTAELLA, L. Redes sociais digitais: a cognição conectiva do Twitter. São Paulo: Paulus, 2010.

LÉVY, P. As tecnologias da inteligência: o futuro do pensamento na Era da Informática. Rio de Janeiro: Editora 34, 1998.

RIBEIRO, D. O processo civilizatório: etapas da evolução sociocultural. São Paulo: Companhia das Letras; Publifolha, 2000. (Grandes nomes do pensamento brasileiro).

WERSIG, G. Information Science.

ROBREDO, J. Do documento impresso à informação nas nuvens: reflexões. In: ENCONTRO NACIONAL DE PESQUISA EM CIÊNCIA DA INFORMAÇÃO, 9, 2010, Rio de Janeiro. Anais... Rio de Janeiro: Ancib, 2010.

ROBREDO, J. Filosofia e Informação? - Reflexões. RICI: R.Ibero-amer. Ci. Inf., ISSN 1983-5213, Brasília,v. 4, n. 2, p. 1-39, ago./dez.2011.

ROCHA LOURES, R.Cidades inovadoras. 2011. Disponível em:

http://www.cidadesinovadoras.org.br/cici2011/. Acesso em: out. 2011. 
PontodeAcesso, Salvador, v.13, n.2, p.238-255,ago. 2019 www.pontodeacesso.ici.ufba.br 